\title{
HISTÓRIA DA LEGISLAÇÃO DO EXERCICIO DA ENFERMAGEM NO BRASIL
}

\author{
HISTORY OF THE NURSING PRACTICE LEGISLATION IN BRAZIL \\ HISTORIA DE LALEGISLACIÓN PARA EL EJERCICIO DE LAENFERMERÍA \\ ENBRASIL
}

Taka Oguisso ${ }^{1}$

\begin{abstract}
RESUMO: Relata a grande contribuição da Associação Brasileira de Enfermagem (ABEn) no estudo, discussão e aprovação das leis e demais atos normativos que causam grande impacto à profissão da enfermagem. Cabe destacar que a ABEn sempre trabalhou de uma forma muito ativa, pacífica, correta e altaneira, com utilização de argumentos técnicos e dados documentais para o convencimento de autoridades legislativas e executivas na busca dos objetivos finais que a classe necessitava.
\end{abstract}

PALAVRAS-CHAVE: legislação em enfermagem, exercício profissional da enfermagem, história da legislação em enfermagem, ABEn

\section{INTRODUÇÃO}

O estudo da historia é importante para descobrir caminhos percorridos pelas gerações passadas e entender as razões que motivaram a escolha de determinados percursos, cujas conseqüências podem estar refletindo na situação presente.

Da mesma forma, o futuro será uma conseqüência ou um reflexo da situação presente. Todas as descobertas científicas, assim como a conquista de grandes feitos em qualquer campo, seja o esportivo, artístico, tecnológico ou social, foram precedidas de muito trabalho, dedicação, perseverança, sacrifício e lutas.

A História da Enfermagem Brasileira está repleta de nomes de grandes è incansáveis pioneiras, cujos feitos se refletem até os dias de hoje e as gerações atuais podem desfrutar dos incontáveis benefícios, especialmente no campo da legislação profissional. Algumas considerações sobre o passado constituem, portanto, ponto de partida indispensável para avaliar os esforços e as lutas que cercaram a promulgação de todos os diplomas legais de determinação do currículo mínimo de enfermagem, de regulamentação do exercício da profissão, ou de controle da classe pela própria classe. Assim, esta resenha constitui um resumo de diversos trabalhos de estudiosos e enfermeiros que testemunharam e/ou acompanharam a evolução da enfermagem no Brasil; que sentiram e viveram as muitas dificuldades e sacrifícios enfrentados pela classe; que vibraram com as conquistas; e por isso mesmo, deixaram para a Enfermagem um patrimônio de tradições e lutas históricas.

Como já se repetiu muitas vezes, a partir da criação da Associação Brasileira de Enfermagem (ABEn), em 1926, pelas formandas da primeira turma da Escola de Enfermeiras do Departamento Nacional de Saúde Publica, atualmente, Escola de Enfermagem Anna Nery, da Universidade Federal do Rio de Janeiro (UFRJ), fundada em 1923, (Decreto 16.300, de 31 de dezembro de 1923) a história da Enfermagem brasileira se confunde com a história da ABEn. (BRASIL, 1974)

${ }^{1}$ Enfermeira e advogada. Professora Titular, do Departamento de Orientação Profissional, da Escola de Enfermagem da Universidade de São Paulo. 
Para fins didáticos e para facilitar a compreensão, o estudo da história da legislação profissional foi elaborado obedecendo-se aos seus diversos campos específicos, ou seja, a legislação do ensino, em nível superior e médio e do exercício profissional separadamente, e em ordem cronológica, embora os fatos possam ter ocorrido de forma concomitante. O presente trabalho, entretanto, inclui apenas a parte do exercício profissional, por entender-se que esse campo abrangerá maior número de interessados nessa leitura.

\section{A LEGISLAÇÃO DO EXERCÍCIO DA ENFERMAGEM}

\section{CONSIDERAÇÕES PRELIMINARES}

O exercício de qualquer trabalho, ofício ou profissão está regulamentado pela Constituição (art. $5^{\circ}$, inciso XIII) (BRASIL, 1989), desde que satisfeitas as qualificações estabelecidas em leis especificas. Denominam-se profissões liberais as atividades desempenhadas com independência e autonomia a uma livre clientela.

Entretanto, dessa idéia não se exclui a possibilidade de ser o profissional ou trabalhador liberal suscetivel de um contrato de trabalho, em que se determine ou se evidencie uma subordinação, regulada e protegida pelas leis trabalhistas. Assim sendo, tradicionalmente, o caráter distintivo da profissão liberal esta principalmente em ser uma profissão cujo exercício depende de conhecimentos acadêmicos específicos ou cujo êxito decorre da maior ou menor capacidade intelectual do profissional. Assim, se o profissional exerce sua profissão aplicando conhecimentos científicos ou intelectuais, não importa que ele a exerça com dependência administrativa ou não. É por essa razão que o exercício da profissão liberal depende de um titulo de habilitação ou qualificação, como um diploma, expedido de acordo com uma lei.

O parâmetro estabelecido em todas as normas legais do País oferece proteção não só aos que exercem a atividade, mas também às pessoas a quem essa atividade é dirigida.

\section{EVOLUÇÃO HISTÓRICA DALEGISLAÇÃO}

Historicamente, a legislação para a formação da parteira, considerando seu vínculo com faculdades de medicina, teve inicio com um Decreto sem número de 3.10.1832 e a do exercício profissional com o Decreto 828, de 29.09.1851, que dispunha sobre o Regulamento da Junta de Higiene Pública, em que os médicos, cirurgiões, boticários, dentistas e parteiras deveriam apresentar seus diplomas na Corte e Província do Rio de Janeiro. Especificamente sobre enfermagem o primeiro dispositivo legal ocorreu somente no alvorecer da República, com o Decreto 791, de 27.09.1890, (BRASIL, 1974) criando a primeira escola profissional de enfermeiros e enfermeiras, de dois anos de duração e aulas ministradas por médicos, atualmente, Escola de Enfermagem Alfredo Pinto, da Universidade do Rio de janeiro (UNIRIO), como relata Moreira (1990). Em 1921 é aprovado um regulamento para o serviço de saúde do Exército, em que os enfermeiros são incluidos como parte do pessoal subalterno, juntamente com padioleiros e outros auxiliares.

Na área civil, o Decreto 15.799, de 10.11.1922, (BRASIL, 1974) aprovou o regulamento do Hospital Geral do Departamento Nacional de Saúde Pública, que na ocasião já mencionava que, anexo ao Hospital, seria criada a Escola de Enfermeiras desse Departamento. Somente em 1923, o Decreto 16.300, de 31.12.1923, (BRASIL, 1974) ao aprovar o regulamento do Departamento Nacional de Saúde Pública e a fiscalização do exercício profissional de médicos, farmacêuticos, dentistas, enfermeiros e parteiras, criou também uma escola para enfermeiras, atualmente, a Escola de Enfermagem Anna Nery, da Universidade Federal do Rio de Janeiro (UFRJ). Na parte referente ao exercício, o enfermeiro vinha enfileirado junto com massagistas, manicuros, pedicuros e optometristas que deveriam incumbir-se do tratamento de doentes. 
Mas, se praticassem atos sem ordem médica sofreriam as penalidades previstas no mesmo regulamento.

O Decreto 20.109, de 15-06-31, declarava em sua ementa, que pretendia regular "o exercício da enfermagem no Brasil e fixar as condições para equiparação das escolas de enfermagem". (BRASIL, 1974) Entretanto, apenas o artigo $1^{\circ}$ tratava do exercicio da enfermagem, ao estipular que somente poderiam usar o título de enfermeiro diplomado, ou as iniciais correspondentes a essas palavras, se o profissional fosse diplomado por escola oficial ou equiparada na forma da lei e tivesse o diploma registrado no Departamento Nacional de Saúde Pública. Os demais artigos eram todos relacionados com o ensino da enfermagem.

Posteriormente, o Decreto 20.931, de 11.01.32, ao dispor sobre a regulamentação e fiscalização do exercício da medicina, odontologia e medicina veterinária, regulava também as profissões do farmacêutico, da parteira e da enfermeira. No tocante à enfermagem, não havia ainda preocupação em definir o que esse profissional deveria fazer, mas era-lhe proibido instalar consultório para atendimento de cliente. O Decreto estipulava que em caso de falta grave, o enfermeiro poderia ser suspenso do exercício ou ser demitido, se exercesse função pública.

A Lei 775, de 06.08.1949, (BRASIL, 1974) dispunha sobre o ensino de enfermagem no País, mas incluiu um preceito referente ao exercício profissional no art. 21, dispondo que "as instituições hospitalares, publicas ou privadas, decorridos sete anos apos a publicação desta lei, não poderiam contratar, para a direção dos seus serviços de enfermagem, senão enfermeiros diplomados". Esse artigo foi de grande valia, uma vez que a Lei $775 / 49$ nunca chegou a ser revogada, e décadas mais tarde, líderes da Enfermagem ainda usavam esse preceito legal.

Somente na década de 50 houve a aprovação de uma lei especifica que tratava efetivamente do exercício da Enfermagem. Foi a Lei no. 2.604, de 17.09.55, (BRASIL, 1974) que definiu as categorias que poderiam exercer a Enfermagem no Pais e revogou diversos dispositivos que tratavam de categorias que seriam posteriormente extintas, mas existiram por muito tempo como grupos residuais da enfermagem. Eram os enfermeiros práticos, os práticos de enfermagem, os enfermeiros assistentes, assistentes de enfermagem, enfermeiro militar, atendentes entre outras inúmeras denominações.

Em abril de 1954, uma comissão governamental que estudava o Plano de Classificação de Cargos dos Servidores Públicos Civis da União publicou os resultados, onde a enfermagem havia sido classificada entre os serviços profissionais de nivel médio, com vencimentos inferiores aos dos técnico-científicos, onde estavam os profissionais de nível universitário. AABEn, na época presidida por Dra. Glete de Alcântara, vinha oferecendo subsídios a essa comissão e manteve encontros formais com seus dirigentes para solicitar revisão dos níveis salariais dos enfermeiros nos serviços públicos federais e autárquicos. Esse estudo, já como projeto de lei, tramitou no Congresso Nacional e acabou sendo aprovado como a Lei no. 3.780, de 12.07.1960, (BRASIL, 1974) dispondo sobre a Classificação de Cargos do Serviço Civil do Poder Executivo, e teve uma grande influência na enfermagem. As diversas denominações existentes, à época, na enfermagem foram reduzidas de acordo com as regras de enquadramento por similaridade de atribuições e responsabilidades. Essa Lei apesar de não tratar especificamente da enfermagem, causou enorme impacto na profissão, pois o enfermeiro foi enquadrado como profissão técnico-científica de nível superior no serviço público federal. Com isso, foi aberto o caminho, para que nos âmbitos estadual e municipal, paulatinamente, fosse o enfermeiro também reconhecido como categoria de nivel universitário com remuneração correspondente.

A ação da ABEn foi decisiva nessa inclusão, tanto em nivel federal, como depois em cada Estado, onde as seções estaduais da ABEn participaram ativamente para que fosse reconhecido o nivel técnico-científico ou universitário aos enfermeiros, no âmbito estadual. Como refere Carvalho (1976), de fato, os primeiros atos legislativos na enfermagem não tiveram a participação direta da ABEn, mas é lícito inferir que esta, perfeitamente entrosada com o Serviço de Enfermeiras do Departamento Nacional de Saúde Pública, não permaneceu totalmente alheia 
às diligências realizadas por esse serviço, das quais resultaram esses atos.

Quase seis anos após a promulgação da Lei 2.604/55, o Decreto no. 50.387, de 28.03.61, (BRASIL, 1974) veio regulamentar o exercício da enfermagem. Pela primeira vez houve uma tentativa de definição do exercicio da enfermagem, porém essa definição estava restrita às seguintes atividades: observação e cuidado de doente, gestante e acidentado; administração de medicamentos e tratamentos prescritos pelo médico; educação sanitária; e, aplicação de medidas de prevenção de doenças. Definiu também todas as categorias que poderiam exercer legalmente a profissão, inclusive as obstetrizes e parteiras. Havia porém indefinição de funções de enfermagem, entre todas as categorias existentes. O enfermeiro era diferenciado das demais categorias por quatro funções, que não eram propriamente de enfermagem. Assim, além de poder exercer "a enfermagem em todos os seus ramos", o enfermeiro poderia administrar serviços de enfermagem; participar do ensino em escolas de enfermagem e de auxiliar de enfermagem ou de treinamento de pessoal; dirigir e inspecionar escolas de enfermagem e participar de bancas examinadoras de práticos de enfermagem em concursos. Havia também artigos que tratavam dos deveres e das proibições para todo o pessoal de enfermagem.

Como o técnico de enfermagem não existia na época da aprovação da Lei 2.604/55 e do Decreto 50.387/61, essa categoria ficaria sem função legal durante os vinte anos após sua criação, não fossem as funções definidas no Parecer do Conselho Federal de Educação no. 3.814/76. (BRASIL, 1976) As funções definidas nesse Parecer para o Técnico de Enfermagem e para o Auxiliar de Enfermagem têm valor histórico, porque na época o texto da legislação do exercicio profissional era ainda um projeto em estudo. Mas, constata-se que as atividades específicas descritas posteriormente na Lei no. 7498/86 (BRASIL, 2001) e no Decreto no. 94.406/87, (BRASIL, 2001) do Exercicio Profissional guardam grande semelhança com as Resoluções do Conselho Federal de Educação, mantendo-se inclusive vários de seus termos. Já o decreto regulamentador faz desdobramentos dessas funções, detalhando e explicitando as ações para cada uma dessas categorias.

AABEn foi a primeira organização profissional de enfermagem a surgir, no País, dentre os três tipos de entidades de classe e foi também responsável pela criação dos outros dois: Conselhos de Enfermagem e Sindicatos de Enfermeiros. Na década de 70, a grande vitória conquistada pela ABEn foi justamente a criação dos Conselhos de Enfermagem e em seguida, na mesma década, os Sindicatos de Enfermeiros. A multiplicação de entidades de classe na enfermagem, como em qualquer outra profissão, é uma decorrência do próprio crescimento e especificação de atribuições.

Muito embora a ABEn, como está registrada em sua história, em inúmeras oportunidades tenha saído em campo para defender interesses, inclusive econômicos da profissão, na verdade ela não tinha e não tem competência legal para isso. Se algumas décadas atrás, essa incompetência não era argüida, hoje já não são admitidas interferências dessa ordem pelos próprios órgãos públicos.

Historicamente os enfermeiros começaram a sentir a necessidade de ver a profissão regulamentada, em face da proliferação de diferentes grupos de pessoas, com pequeno ou nenhum preparo, desenvolverem também atividades de enfermagem. A solução, identificada pelas enfermeiras pioneiras na ocasião, era a criação de um Conselho de Enfermagem.

Vinte e oito anos de luta foram necessários para que a ABEn conseguisse tornar realidade a Lei que recebeu o número 5.905, (BRASIL, 1973) de 13 de julho de 1973 e que criou os Conselhos Federal (COFEN) e Regionais de Enfermagem (COREN), estes em âmbito estadual. Mesmo não estando, na época, ainda regulamentadas as funções dos técnicos de enfermagem, o COFEN, fundamentando-se na legislação do ensino, criou três quadros distintos para fins de inscrição: Quadro I, de enfermeiros e obstetrizes; Quadro II, de técnicos de enfermagem; e, Quadro III de auxiliares de enfermagem, práticos de enfermagem e parteiras práticas.

A Lei 7498, de 25-06-86, e o Decreto 94.406, (BRASIL, 2001) de 08-06-87, constituem os 
atuais dispositivos legais do exercício profissional da Enfermagem, e vieram substituir a Lei 2.604/55 e o Decreto 50.387/61 que tiveram vigência por mais de duas décadas. Na nova Lei não houve uma redefinição do que seria a enfermagem, mas estabelece as competências privativas do enfermeiro, inclusive no tocante a consulta e prescrição da assistência de enfermagem e os cuidados de enfermagem de maior complexidade técnica, inexistentes na legislação anterior.

Foram também incluídas as atribuições dos técnicos e auxiliares de enfermagem, sempre sob orientação e supervisão do enfermeiro. Essa Lei, no art. 23, dava um prazo de dez anos, a contar da promulgação da mesma, isto é, 1986, para que o pessoal que estivesse executando tarefas de enfermagem, sem possuir formação especifica, pudesse continuar a exercer essas atividades, desde que devidamente autorizado pelo Conselho Federal de Enfermagem (COFEN). Isso significava que findos os dez anos, isto é, em 1996, todos deveriam estar devidamente qualificados. Entretanto, a Lei 8967, (BRASIL, 1994) de 28-12-94, veio alterar a redação do art. 23 da Lei 7.498/86, assegurando "aos atendentes de enfermagem admitidos antes da vigência desta Lei, o exercício das atividades elementares de enfermagem", sob supervisão do enfermeiro.

\section{SITUAÇÃO ATUALDALEGISLAÇÃO DO EXERCICIO}

A Constituição Brasileira, (BRASIL, 1989) de 1988, assegura a todos os direitos à saúde, sob responsabilidade do Estado (art.196), mediante políticas sociais e econômicas que visem à redução do risco de doenças e de outros agravos assim como o acesso universal e igualitário aos serviços que visem à promoção, proteção e recuperação da saúde. Dá prioridade às ações e serviços públicos de saúde integrantes de um sistema regionalizado e hierarquizado que constituem sistema único de saúde (SUS), e admite que a iniciativa privada também pode oferecer serviços de assistência à saúde.

A Constituição afirma ainda que "é livre o exercício de qualquer trabalho, ofício ou profissão, atendidas as qualificações profissionais que a lei estabelecer" (art. $5^{\circ}$, item XIII)

A Lei das Contravenções Penais (art. 47) (BRASIL, 1985) prevê que "exercer profissão ou atividade econômica, ou anunciar que a exerce, sem preencher as condições a que por lei está subordinado o seu exercício" constitui uma contravenção penal (infração menor que o crime) sujeita à pena de prisão simples ou multa. O elemento moral das contravenções é a simples voluntariedade da ação ou omissão, isto é, para o reconhecimento de fato contravencional, não há necessidade de dolo (intenção) ou de culpa.

O Código Civil Brasileiro, art. $3^{\circ}$ dispõe que "ninguém se escusa de cumprir a lei, alegando que não a conhece". Esse dispositivo é ratificado pelo Código Penal art. 21, (BRASIL, 1985) que estabelece que "o desconhecimento da lei é inescusável. O erro sobre a ilicitude do fato, se inevitável, isenta de pena; se evitável, poderá diminui-la de um sexto a um terço".

Assim, que qualificações ou condições seriam aquelas? Não se trata evidentemente de uma qualificação, capacidade ou aptidão física ou mental e nem mesmo técnica, mas de capacidade legal. Obviamente, capacidade legal supõe capacidade técnica e profissional, mas só esta é insuficiente para o exercício legal da profissão. É o que ocorre com as pessoas formadas em outros paises, que, para trabalharem em nosso pais, necessitam revalidar ou registrar seus títulos. Pode ocorrer também com qualquer pessoa que, estando formada, não registra seu título em órgão disciplinador do exercício.

É necessário lembrar também que a atual Constituição brasileira (art. $5^{\circ}$, inciso XXXII) já previa que o Estado promoveria a defesa do consumidor, e que competia à União (art. 24, inciso VIII) legislar sobre responsabilidade por dano ao consumidor. Com isso, a aprovação do Código de Defesa do Consumidor, (BRASIL, 1998) Lei no. 8.078, de 11-09-90, era uma conseqüência da Constituição. Esse Código afirma que a proteção da vida, saúde e segurança constituem um dos direitos básicos do consumidor contra riscos provocados por serviços considerados perigosos ou nocivos. Neste caso o profissional de enfermagem seria o fornecedor ou prestador do serviço 
e o cliente/paciente o consumidor desse serviço. Além disso, a liberdade de exercer a profissão ou atividade, assegurada pela Constituição, estará limitada pelas condições de qualificação profissional que a lei estabelecer. No caso da enfermagem qual seria essa lei?

\section{LEGISLAÇÃO PROFISSIONAL DE ENFERMAGEM}

A Lei $n^{\circ} 7.498$, (BRASIL, 2001) de 25 de junho de 1986, regulamentada pelo Decreto 94.406, de 8 de junho de 1987, trata do exercício profissional da enfermagem. Essa Lei dispõe em seu art. $1^{\circ}$ que "é livre o exercício da enfermagem em todo o território nacional, observadas as disposições desta Lei".

Em que consiste o exercicio da enfermagem? Quem pode exercer legalmente a profissão de enfermagem no País?

A resposta é dada pelo Decreto $n^{\circ}$ 94.406, (BRASIL, 2001) de 8 de junho de 1987, que especifica que "o exercício da atividade de enfermagem, observada as disposições da Lei 7.498/ 86, e respeitados os graus de habilitação, é privativo do Enfermeiro, Técnico de Enfermagem, Auxiliar de Enfermagem e Parteiro e só será permitido ao profissional inscrito no Conselho Regional de Enfermagem da respectiva Região". Além de definir quem são cada um dos profissionais antes mencionados, o Decreto 94.406/87 descreve as atribuições para cada uma dessas categorias do pessoal de enfermagem. Para o enfermeiro são descritas as atividades privativas e as que deve realizar como integrante de equipe de saúde. Portanto, aquele que não possui um desses títulos também não pode, legalmente, exercer a enfermagem.

Em virtude da carência de recursos humanos de nível médio nessa área, entretanto, a Lei 7.498/86, (BRASIL, 2001) no art. 23, permitiu que o pessoal, sem formação especifica, tais como os atendentes de enfermagem e agentes de saúde, que se encontravam executando tarefas de enfermagem continuassem nessa atividade desde que autorizado pelo Conselho Federal de Enfermagem. Porém, essa autorização, que expiraria em junho de 1996, isto é, dez anos após a promulgação daquela Lei, teve seu texto alterado pela Lei 8.967, (BRASIL, 1994) de 28 de dezembro de 1994, conforme acima mencionado.

Portanto, não existe mais prazo legal que obrigue as pessoas amparadas pela Lei $8.967 /$ 94 (BRASIL, 1994) a buscar uma formação especifica. O Ministério da Saúde, preocupado com o problema, através de projetos como o PROFAE - Projeto de Profissionalização dos Trabalhadores da área de Enfermagem, pretende profissionalizar esses trabalhadores, inclusive os atendentes de enfermagem, a fim de melhorar a qualidade dos serviços de saúde.

A titularidade constitui, pois, condição de capacidade técnica para o exercício profissional em qualquer profissão. Dai a importância que a lei confere à qualificação ou ao título profissional de acordo com o grau de preparo e formação. Por isso, na divisão do trabalho de enfermagem, as atividades mais complexas e de maior responsabilidade foram atribuidas aos enfermeiros, profissionais de maior preparo acadêmico.

O Decreto 94.406/87 (BRASIL, 2001) é muito claro (art. $8^{\circ}$ ) sobre aquelas atividades privativas de direção e liderança do enfermeiro, assim como de planejamento, organização, coordenação, execução e avaliação da assistência de enfermagem exercida nos órgãos de enfermagem, aqui incluídos todos os niveis da estrutura institucional, pública ou privada, tais como coordenadorias, consultorias, auditorias, assessorias, departamentos, divisões, serviços ou seções de enfermagem. Além dessas atividades de cunho intelectual ou administrativo, cabem ainda ao enfermeiro em caráter privativo a consulta e prescrição da assistência de enfermagem, assim como os cuidados diretos de enfermagem a pacientes graves com risco de vida e os de maior complexidade técnica e que exijam conhecimentos científicos adequados e capacidade de tomar decisões imediatas.

Como integrante de equipe de saúde, o enfermeiro tem no inciso II do mesmo art. $8^{\circ}$, um elenco de 17 atividades, onde ele participa na elaboração, no planejamento, execução e avaliação 
de planos e programas de saúde, de assistência integral à saúde individual e de grupos específicos, particularmente daqueles prioritários e de alto risco, prevenção e controle da infecção hospitalar, de educação sanitária, de vigilância epidemiológica, de projetos de construção ou reforma de unidades de saúde, de treinamento de pessoal de saúde, assim como na prestação de assistência obstétrica e execução de parto sem distócia, em situação de emergência, entre outras funções.

Os profissionais portadores do título de obstetriz, enfermeira obstétrica (art. $9^{\circ}$ ) ou enfermeiro obstetra (art. 12, parágrafo único), além das atividades já mencionadas, podem também: prestar assistência obstétrica à parturiente e ao parto normal, assim como identificar distócias obstétricas e tomar providências até a chegada do médico e realizar episiotomias e episiorrafias, com aplicação de anestesia local, quando necessária. O parteiro ou parteira pode prestar assistência à gestante e à parturiente, assistir ao parto normal, inclusive em domicilio e cuidar da puérpera e do recém-nascido. Essas atividades devem ser exercidas sob supervisão de enfermeira obstétrica, quando realizadas em instituições de saúde e, sempre que possível, sob controle e supervisão de unidades de saúde, quando realizadas em domicílio.

As funções dos técnicos de enfermagem e dos auxiliares de enfermagem também estão descritas no mesmo Decreto (art. 10 e 11), cabendo-lhes atividades auxiliares de nivel médio técnico, inclusive as de assistência de enfermagem, excetuadas as privativas do enfermeiro e as especificas de assistência obstétrica referidas no artigo $9^{\circ}$ desse Decreto.

Todos os profissionais de enfermagem devem sempre ter à mão o texto da Lei 7.498/86 e do Decreto 94.406/87 para poderem consultar e esclarecer dúvidas, sempre que necessário. Os CORENS, de um modo geral, têm publicado exemplares em tamanhos variados tanto da Lei e seu Decreto, como do Código de Ética dos Profissionais de Enfermagem (COFEN, 2001) (Resolução COFEN 240/2000) que facilita tê-los no bolso ou bolsa. Dada essa facilidade, não se acrescentam esses textos como anexo ao presente trabalho, pelo contrário, estimula-se sua aquisição ou busca na sede da entidade de seu respectivo Estado.

A Associação Brasileira de Enfermagem, na época presidida por Dra. Circe de Melo Ribeiro, teve influência decisiva na inclusão de uma descrição pormenorizada e avançada das funções características e típicas de muitas especialidades dos enfermeiros, na publicação "Classificação Brasileira de Ocupações" pelo Ministério do Trabalho, em 1977, antes mesmo que algumas dessas especialidades se firmassem no cenário dos serviços de saúde, em hospitais, ambulatórios e outros. Essa descrição ajudou até mesmo na inserção de alguns desses especialistas nos respectivos campos de trabalho, como ocorreu, por exemplo, com o enfermeiro do trabalho. A Classificação Brasileira de Ocupações, (BRASIL, 1994) cuja última versão foi publicada pelo Ministério do Trabalho em 1994, é um documento pouco divulgado entre enfermeiros e demais membros da equipe de enfermagem, mas deveria ser melhor conhecido pelos profissionais interessados em um documento governamental que descreve os parâmetros do exercício da enfermagem, conforme recomendam Oguisso Schmidt (1999).

Finalmente, o Conselho Federal de Enfermagem (COFEN), por meio da Resolução 186/ 95, define e especifica as atividades elementares de enfermagem, executadas por atendentes e pessoal assemelhado, isto é, pessoal sem formação especifica regulada em lei, como sendo aquelas que "compreendem ações de fácil execução e entendimento, baseadas em saberes simples, sem requererem conhecimento cientifico, adquiridas por meio de treinamento e/ou prática; requerem destreza manual, se restringem a situações de rotina e de repetição, não envolvem cuidados diretos ao paciente, não colocam em risco a comunidade, o ambiente e/ou a saúde do executante, mas contribuem para que a assistência de enfermagem seja mais eficiente". Essas atividades relacionam-se basicamente com a higiene, conforto e transporte do paciente, com a organização do ambiente, com as consultas, exames e tratamentos e com o óbito. 


\section{OS VETOS AO PROJETO DE LEI}

Alguns artigos da Lei 7.498/86 (BRASIL, 2001) foram vetados pelo Presidente da República e houve outros dispositivos que não haviam sido incluidos. Entre eles encontravam-se dispositivos arrojados que os líderes de enfermagem, na época, tentaram assegurar aos enfermeiros, tais como: a inclusão obrigatória de órgãos de enfermagem na estrutura da administração superior (art. $5^{\circ}$ ); autonomia técnica no planejamento, execução e avaliação dos serviços e da assistência de enfermagem (art. 10); exercício privativo de direção de escola, chefia de departamento e coordenação de cursos para formação de pessoal de enfermagem em todos os graus (art. 11, inciso d); a inclusão do ensino de enfermagem de $1^{\circ}$ grau como parte das atribuições do enfermeiro e do técnico de enfermagem; o exercício do magistério nas disciplinas específicas de enfermagem, no $2^{\circ}$. e $3^{\circ}$. graus, obedecidas às disposições legais relativas ao ensino; entre outros.

O Projeto de Lei, porém, não continha dispositivos referentes a dimensionamento dos recursos humanos necessários para uma adequada assistência de enfermagem, assim como os relacionados com as condições de trabalho. Estes são, na verdade aspectos complexos, porque dependem de planta física, tipo e caracteristicas da instituição, caracteristicas da clientela atendida e tipos de cuidados que necessitam (intensivos, semi-intensivos, intermediários, prolongados, mínimos, ambulatoriais, residenciais ou domiciliárias), características do serviço de enfermagem (filosofia, programas, categorias do pessoal, horários de trabalho) e poderia competir à chefia de um serviço de enfermagem, dimensionar no seu local de trabalho a quantidade, por categoria dos recursos humanos necessários, para poder oferecer serviços de enfermagem com a qualidade requerida. Oliveira (1986) refere mesmo que se o Projeto de Lei não atendia, por inteiro, todas as aspirações profissionais dos enfermeiros, até porque muitas delas podiam ser incorporadas ou desdobradas posteriormente em seu regulamento, era importante verificar-se os grandes avanços que a profissão poderia alcançar com a aprovação do texto como ele se encontrava.

O desconhecimento, pelos legisladores e autoridades do País, da verdadeira dimensão da enfermagem como profissão, com seus estudos e pesquisas, ou o temor de estarem concedendo excessivo poder ao enfermeiro, bem como a existência de legislação específica na área de educação talvez possa explicar os vetos e a falta de acolhida a essas propostas dos líderes da enfermagem da época.

\section{CONCLUSÕES}

Como se vê enfermeiros e profissionais de enfermagem ainda têm muito a lutar para ver reconhecidas a capacidade e potencialidade profissionais. Entretanto, a sociedade não Ihes dará esse reconhecimento como uma dádiva, mas deverá ser conquistado com maior envolvimento das novas gerações de enfermeiros, não apenas como bons profissionais de ensino, de assistência ou de pesquisa, mas também no campo sócio-político, dentro do cenário brasileiro, começando pelos órgãos de classe como a Associação Brasileira de Enfermagem, dai ascendendo para posições no legislativo e no executivo, seja no âmbito municipal, estadual ou federal.

Há exemplos, no passado, não muito distante de um enfermeiro, Samora Machel, que tendo sido um militante enfermeiro, passou a lutar pela independência de seu pais e terminou vitorioso em 1975, quando se tornou o primeiro presidente da República de Moçambique. Em outro país africano, Angola, três enfermeiros já ocuparam o cargo de Ministro da Saúde. Mas, mesmo na Europa e na Ásia há exemplos de enfermeiros que ocuparam esse cargo nas décadas de 80 e 90.

É necessário que os atuais líderes da profissão comecem a preparar o terreno, descobrindo os futuros lideres e preparando-os para assumir sua posição na sociedade, traçando 
as metas desejadas e elaborando as estratégias que possibilitem alcançá-las. Só assim, seria possivel deixar para as novas gerações uma Enfermagem abrangente, respeitada e profissionalmente valorizada.

ABSTRACT:This article outlines the contribution of the Brazilian Association of Nursing (ABEn) in the study, discussion and approval of laws and regulations that have significant impact on the nursing profession. It points out that ABEn has always had an active, pacific and accurate way of working. It emphasizes that the association has dealt with de law making-body and executive members of the government, based on technical arguments and secondary data in order to comply with the nursing professional's needs.

KEYWORDS: nursing legislation, nursing professional practices, history of the nursing legislation

RESUMEN - Relata la contribución que la Asociación Brasileña de Enfermería (ABEn) ha dado para el estudio, discusión y aprobación de las leyes y demás actos normativos que han traído un gran impacto positivo a la profesión de enfermeria. Cabe destacar que la ABEn siempre ha trabajado de una forma muy activa, pacífica, correcta y digna, con argumentos técnicos y datos documentales para convencer a las autoridades legislativas y ejecutivas en la búsqueda y alcance de los objetivos finales que la clase ha necesitado.

PALABRAS CLAVE: legislación en enfermería, ejercicio profesional de la enfermeria, historia de la legislación en enfermería

\section{REFERÊNCIAS BIBLIOGRÁFICAS}

BRASIL. Decreto n. 828, de 29 de setembro de 1851. Manda executar o regulamento da Junta de Hygiene Pública. In: Brasil. Leis, decretos, etc. Colecção das Leis do Império do Brasil. Rio de Janeiro: Typographia Nacional. Tomo 14, parte 2a, Seção 59, p. 259.

BRASIL. Decreto 791, de 27-09-1890. Cria no Hospício Nacional de Alienados uma escola profissional de enfermeiros e enfermeiras. Enfermagem, legislação e assuntos correlatos. 3. ed. Rio de Janeiro: Ministério da Saúde/Fundação Serviços de Saúde Pública, 1974. v. 1, p.26-27.

BRASIL. Decreto no. 15.799, de 10-11-22. Aprova o regulamento do Hospital Geral de Assistência do Departamento Nacional de Saúde Pública. Enfermagem, legis/ação e assuntos correlatos. 3. ed. Rio de Janeiro: Ministério da Saúde/Fundação Serviços de Saúde Pública, 1974. v. 1, p.55-6.

BRASIL. Decreto 16.300, de 31-12-23. Aprova o regulamento do Departamento Nacional de Saúde Pública. Enfermagem, legis/ação e assuntos correlatos. 3. ed. Rio de Janeiro: Ministério da Saúde/ Fundação Serviços de Saúde Pública, 1974. v. 1, p.57-66.

BRASIL. Decreto 20.109, de 15-06-31. Regula o exercício da enfermagem no Brasil e fixa as condições de equiparação das escolas de enfermagem. Enfermagem, legis/ação e assuntos correlatos. 3. ed. Rio de Janeiro: Ministério da Saúde/Fundação Serviços de Saúde Pública, 1974. v. 1, p.68-72.

BRASIL. Código Penal, 1940. Novo Código Penał. Decreto-lei n. 2848, de 07-12-1940, atualizado pela Lei n. 7209, de 11-7-1984. 23. ed. São Paulo: Saraiva, 1985

BRASIL. Lei das Contravenções Penais. Decreto n. 3688, de 03-10-1941. São Paulo: Saraiva, 1985 Art. 47. 
BRASIL. Lei n. 775, de 6 de agosto de 1949. Dispõe sobre o ensino de enfermagem no País e dá outras providências. Enfermagem, legislação e assuntos correlatos. 3. ed. Rio de Janeiro: Ministério da Saúde/Fundação Serviços de Saúde Pública, 1974. v. 1, p. 154-157.

BRASIL. Lei n. 2.604, de 17 de setembro de 1955. Regula o exercício da enfermagem profissional. In: Ministério da Saúde, Fundação Serviços de Saúde Pública, Enfermagem, legis/ação e assuntos correlatos. 3. ed. v. 1, p. 177-179.

BRASIL. Lei 3.780, de 12 de julho de 1960. Dispõe sobre a Classificação de Cargos do Serviço Civil do Poder Executivo, estabelece os vencimentos correspondentes e dá outras providências. Enfermagem, legis/ação e assuntos correlatos. 3. ed. Rio de Janeiro: Ministério da Saúde/Fundação Serviços de Saúde Pública, 1974. v. 1, p. 188-209.

BRASIL. Decreto 50.387, de 28-03-61. Regulamenta o exercício da enfermagem e suas funções auxiliares no território nacional. Enfermagem, legislação e assuntos correlatos. 3. ed. Rio de Janeiro: Ministério da Saúde/Fundação Serviços de Saúde Pública, 1974. v. 1, p. 217-222.

BRASIL - Ministério da Educação e Cultura. Parecer 3814/76. Documenta, Brasília, n. 192, p. 17-32, Brasília, 1976

BRASIL. Lei n. 5.905, de 12 de julho de 1973. Dispõe sobre a criação dos Conselhos Federal e Regionais de Enfermagem e dá outras providências. Diário Oficial da Uniāo, Brasília, 18 de jul de 1973. Seção 1

BRASIL. Lei 7498, de 25-07-86, dispõe sobre a regulamentação do exercício da Enfermagem e da outras providências. In: Conselho Regional de Enfermagem, COREN-SP. Documentos básicos de Enfermagem. São Paulo, 2001.

BRASIL. Decreto 94.406, de 08.06.87. Regulamenta a Lei no. 7498/86, que dispõe sobre o exercício da enfermagem e dá outras providências. In: Conselho Regional de Enfermagem, COREN-SP, Documentos básicos de Enfermagem. São Paulo, 2001.

BRASIL. Constituição da República Federativa do Brasil, promulgada em 5 de outubro de 1988. Série Legislação Brasileira, organizada por Juarez de Oliveira. 2. ed. São Paulo: Saraiva, 1989.

BRASIL. Lei n. 8078, de 11 de setembro de 1990. Dispõe sobre a proteção do consumidor e dá outras providências. In: COD/GO do Consumidor. Rio de Janeiro: Esplanada, 1998. (Coleção ADCOAS).

BRASIL. Ministério do Trabalho. Secretaria de Políticas de Emprego e Salário. Classificação Brasileira de Ocupações - CBO-94. Brasília, 1974. p. 101-105, 138, 145, 282-285.

BRASIL. Lei n 8967, de 28 de dezembro de 1994. Altera a redação do art. 23 da Lei n. 7.498, de 2506-1986. Assegura ao atendente admitido antes da vigência desta Lei, o exercício das atividades elementares de enfermagem, observado o disposto no art. 15. Diário Oficial da União, Brasília, 29 de dez. de 1994

CARVALHO, A.C. Associação Brasileira de Enfermagem. 1926-1976, Documentário. Brasília: ABEn, 1976

CONSELHO FEDERAL DE ENFERMAGEM (COFEN) - Resolução 186/95. Dispõe sobre a definição e especificação das atividades elementares de enfermagem executadas pelo pessoal sem formação específica regulada em lei. Documentos básicos de Enfermagem. São Paulo: COREN-SP, 2001. p. $142-143$ 
CONSELHO FEDERAL DE ENFERMAGEM (COFEN) - Resolução 240/2000. Código de Ética dos Profissionais de Enfermagem. Documentos básicos de Enfermagem. São Paulo: COREN-SP, 2001. p. $277-289$

MOREIRA, A. Escola de Enfermagem Alfredo Pinto - 100 anos de História. 1990. Dissertação (Mestrado) - Universidade do Rio de Janeiro - UNIRIO, Rio de Janeiro.

OGUISSO, T; SCHMIDT, M.J. O exercicio da enfermagem - uma abordagem ético-legal. São Paulo: LTr, 1999.

OLIVEIRA, M.I.R. - Ética e Legislação na Enfermagem - comentários gerais. Rev.Bras. Enf, Brasília, v. 39, n. 1, p. 67-70, jan./mar. 1986. 